\title{
Investigação-ação com mães de pessoas com deficiência intelectual: a redução da sobrecarga como um projeto de vida
}

Action Research with mothers of people with intellectual disabilities: reducing overload as a life project

Investigación Acción con madres de personas con discapacidad intelectual: reducir la sobrecarga como proyecto de vida

\section{Sarah Cecílio Fonseca}

Mestranda na Universidade Federal de São João Del-Rei, São João Del-Rei, Minas Gerais, Brasil. sarahcecilio@hotmail.com

ORCID - https://orcid.org/0000-0002-2449-1938

Maria Nivalda de Carvalho-Freitas

Professora doutora na Universidade Federal de São João Del-Rei, São João Del-Rei, Minas Gerais, Brasil. nivalda@ufsj.edu.br

ORCID - https://orcid.org/0000-0001-7071-7179

\section{Beatriz André Alves}

Graduada na Universidade Federal de São João Del-Rei, São João Del-Rei, Minas Gerais, Brasil. bia.a.alves@hotmail.com

ORCID - https://orcid.org/0000-0002-5551-7643

Recebido em 4 de outubro 2019

Aprovado em 21 de junho de 2020

Publicado em 8 de julho de 2020

\section{RESUMO}

O artigo tem por objetivo relatar investigação-ação realizada com grupos de mães de pessoas com deficiência intelectual, visando contribuir para a melhoria na qualidade de vida e na ressignificação de seus projetos de vida. A investigação-ação foi realizada com dois grupos, sendo que em um deles realizou-se 24 encontros durante oito meses, e, no outro, foram realizados 12 encontros durante quatro meses. Foram registrados todos os encontros, através de observações sistemáticas, e realizada a análise de conteúdo e dos principais fenômenos grupais, além de avaliação da percepção de mudança após finalização da experiência. No início da pesquisa, observou-se resistência por parte das mães em relação ao tema projeto de vida como consequência de dificuldades pouco trabalhadas em relação à capacidade de seus filhos. Isto é, observou-se que as mães ofereciam poucas possibilidades de seus filhos desenvolverem autonomia e independência para atividades da vida diária, causando sobrecarga às mesmas, enquanto cuidadoras. Assim, o foco da investigação-ação foi discutir sobre atividades concretas que pudessem gerar autonomia, considerando os limites e as possibilidades dos filhos e questões relacionadas às vivências subjetivas das mães, tendo como disparador o Inventário de Habilidades de Vida Independente. Verificou-se que a reflexão sobre atividades diárias dos filhos, sobre formas de estimulação para maior independência e sobre estratégias que poderiam ser utilizadas para o filho desenvolver determinado comportamento, além de reduzir a sobrecarga, constitui-se em um projeto de vida para as mães. 
http://dx.doi.org/10.5902/198468640373

Palavras-chave: Deficiência intelectual; sobrecarga; projeto de vida.

\section{ABSTRACT}

The article aims to report action research conducted with groups of mothers of people with intellectual disabilities, aiming to contribute to the improvement in the quality of life and the re - signification of their life projects. The action research was fulfilled with two groups, and in one of them 24 meetings were held during eight months, and in the other, 12 meetings were held during four months. All the meetings were recorded through systematic observations. An analysis of content and main group phenomena, as well as evaluation of perception of change, after completion of the experiment was also developed. At the beginning of the research, there was resistance on the part of the mothers in relation to the project of life as a consequence of little some difficulties in relation to the capacity their children.That is, it was observed that the mothers offered little possibilities for their children to develop autonomy and independence for activities of the daily life, causing them to be overloaded while caregivers. Thus, the focus of the action research was to discuss concrete activities that could generate autonomy, considering the limits and possibilities of the children and questions related to the subjective experiences of the mothers, taking as a trigger the Inventory of Independent Living Skills. It was found that the reflection on the daily activities of the children, on ways of stimulation for greater independence and on strategies that could be used for the child to develop certain behavior, besides reducing the overload, is a life project for mothers.

Keywords: Intellectual disabilities; overlaod; life project.

\section{RESUMEN}

El artículo tiene como objetivo relatar la investigación acción realizada con grupos de madres de personas con discapacidad intelectual, buscando contribuir a la mejora en la calidad de vida y en la resignificación de sus proyectos de vida. La investigación acción se realizó con dos grupos, siendo que en uno de ellos se realizaron 24 encuentros durante ocho meses, y en el otro, se realizaron 12 encuentros durante cuatro meses. Se realizó el registro de todos los encuentros, a través de observaciones sistemáticas y realizando análisis de contenido y de los principales fenómenos grupales, además de evaluaciones de la percepción de cambio post finalización de la experiencia. En el inicio de la investigación , se observó resistencia por parte de las madres en relación al tema proyecto de vida como consecuencia de dificultades poco trabajadas en relación a la capacidad de sus hijos.Es decir, se observó que las madres ofrecían pocas posibilidades para que sus hijos desarrollaran autonomía e independencia para actividades de la vida diaria, causando sobrecarga a las mismas, como cuidadoras. Así, el foco de la investigación acción fue discutir sobre actividades concretas que pudieran generar autonomía, considerando los límites y posibilidades de los hijos y cuestiones relacionadas a las vivencias subjetivas de las madres, teniendo como desencadenante el Inventario de Habilidades de Vida Independiente. Se encontró que la reflexión sobre las actividades diarias de los niños, sobre las formas de estimulación para una mayor independencia y sobre las estrategias que podrían usarse para que el niño desarrolle cierto comportamiento, además de reducir la sobrecarga, constituye un proyecto de vida para las madres.

Palabras clave: Discapacidad intelectual; sobrecarga; proyecto de vida.

\section{Introdução}


http://dx.doi.org/10.5902/198468640373

A deficiência intelectual (DI) é definida por limitações significativas no funcionamento intelectual, que se refere à capacidade mental geral, como a aprendizagem, o raciocínio ou a resolução de problemas; bem como no comportamento adaptativo, que compreende habilidades sociais e práticas cotidianas. Para o seu diagnóstico, é importante considerar as limitações do funcionamento do indivíduo dentro de contextos de ambientes típicos de indivíduos da mesma faixa etária e, principalmente, da mesma cultura (AMERICAN ASSOCIATION ON INTELLECTUAL AND DEVELOPMENTAL DISABILITIES / AAIDD 2010). No país, existem 2.617.025 pessoas com DI - 1,37\% da população brasileira (INSTITUTO BRASILEIRO DE GEOGRAFIA E ESTATÍSTICA / IBGE, 2012). A importância do cuidado à pessoa com DI compreende não só o aspecto biológico, mas também social e ambiental (TOMAZ et al., 2016), baseando sua compreensão diretamente em concepções, percepções e valores culturais (CARVALHO; MACIEL, 2003).

De acordo com Batista e França (2007), o nascimento de uma criança com DI na família é considerado um evento traumático, de mudanças, dúvidas e confusão, e Mishler (2002) aponta que a confirmação de um filho com um problema de saúde que demandará cuidados constantes é considerado um ponto de virada, ou mudança, na vida dos pais. Assim, é necessário aprender a lidar com a dissonância entre a imagem que se criou da criança que estava por vir com o que ela realmente é; o que é mais difícil para os pais que se encontram nesta situação (JERUSALINSKY, 2007; KLAUS; KENNELL; KLAUS, 2000).

Pesquisa realizada por Carvalho, Ardore e Castro (2015) indica que, na maioria das vezes, a mãe é a cuidadora principal até o envelhecimento de ambos. Segundo Cavalcante (2001), inserida na cultura em que o papel do pai não é o mais valorizado, a própria mãe julga-se a única e principal responsável por ter gerado este filho. Sendo assim, a sobrecarga materna mostra-se evidente, já que as mães fazem intensas mudanças, tanto na vida profissional quanto pessoal, para cuidar do filho com DI (RABELO; ALVES; SOUZA, 1999; WALDMAN; SWERDLOFF; PERLMAN, 1999). Entende-se sobrecarga como uma alta demanda de cuidados que requerem adaptações no cotidiano e interferem nas necessidades do cuidador gerando acúmulo de responsabilidades, adiamento de planos pessoais (MARTENS; ADDINGTON, 2001), alteração da vida pessoal e profissional, mudanças de rotina e excesso de trabalho (MARRON et al., 2013).

Segundo Coll, Marchesi e Palacios (2004), é comum as mães questionarem a maturidade e a independência que os filhos podem vir a adquirir, e, em estudo realizado por Bastos e Deslandes (2008), é demonstrado o conflito das mesmas entre identificar 
http://dx.doi.org/10.5902/198468640373

comportamentos de integração em grupos sociais etários e reconhecer profundas distâncias de uma adolescência da pessoa sem DI, o que causa, segundo Chacon (1999), confusão entre ações restritivas e estimulantes para o filho.

Por outro lado, as pessoas com DI têm superado a expectativa de vida (COPPUS, 2013), o que gera desafios para a sociedade. Assim, Carvalho, Ardore e Castro (2015) destacam a importância em discutir e refletir sobre as novas formações familiares e os cuidados para esta população, no intuito de promover assistência e qualidade de vida. Haley e Pekins (2004) destacam dificuldades em relação ao envelhecimento da família, mas que, por ser uma população oculta, reluta em procurar ajuda. Ward e Cooper (2013) ressaltam a importância de compreender as razões geradoras de angústias vivenciadas ao longo da vida do filho. Além disso, Carvalho, Ardore e Castro (2015) apontam que são comuns situações de estresse prolongado e isolamento social por parte das mães.

Por diversos motivos, como a experiência do estigma devido à suposta incapacidade social (CORCORAN; BERRY; HILL, 2015), o sentimento de culpa, o desconforto com o diagnóstico, a dificuldade de compreensão e a falta de informação acerca da deficiência (BASTOS; DESLANDES, 2008), a convivência com este membro pode tornar-se uma situação complexa e acarretar experiência de estresse, comprometendo diversas esferas psicológicas, emocionais, sociais e funcionais (SANTOS; PEREIRA-MARTINS, 2016). Um estudo realizado com pais e mães de crianças com DI e sem DI observou escores elevados de depressão e ansiedade nos primeiros, de modo que a sobrecarga e o sentimento de culpa foram os fatores de mais destaque para o desenvolvimento desses tipos de sofrimento psicológico (GALLAGHER et al., 2008).

Com isto, observa-se a demanda, por parte da mãe que envelhece, de atendimento, acompanhamento e orientações, na garantia de manutenção da saúde e promoção da qualidade de vida (BEMISTER et al., 2015; YOONG; KORITSAS, 2012). Nestes casos, tem sido indicada a rediscussão acerca do projeto de vida, tanto da pessoa com DI quanto da mãe. Este trabalho deve incluir a separação pela morte, aspectos de saúde e condições socioeconômicas, antes mesmo destas questões tornarem-se relevantes (CARVALHO; ARDORE; CASTRO, 2015). Para lidar com todo este estresse parental, as pesquisas têm indicado que é necessário o apoio de uma rede social para melhor enfrentamento da situação (DOUMA; DEKKER; KOOT, 2006), sendo este um recurso de melhor adaptação à situação exposta (MATSUKURA et al., 2007). De acordo com Nobre, Montilha e Temporini (2008), grupos de encontro proporcionam a troca de informações e de experiências acerca 
http://dx.doi.org/10.5902/198468640373

da deficiência. Em pesquisa realizada pelas autoras, os relatos das mães demonstram que, além da melhor adaptação e troca de experiências, o grupo ajuda a esclarecer dúvidas e expor sentimentos, proporcionando discussões referentes à deficiência que, por vezes, elas não podem, não querem ou não conseguem conversar com outros familiares ou profissionais; além de construírem uma relação mais positiva com a deficiência, diminuindo preconceitos próprios e criando alternativas para lidar com o preconceito do próximo, podendo conceber novos horizontes para o desenvolvimento do filho (RIBEIRO; YAMADA; TAVANO, 2007).

Desta forma, o grupo coloca-se como um meio facilitador para conhecer outras mães na mesma situação e dividir dificuldades e anseios. Neste sentido, enfatizam-se os ganhos para as mães ou cuidadoras, na tentativa de compreender a família a partir de um contexto mais amplo da saúde (RIBEIRO; YAMADA; TAVANO, 2007).

Considerando o cenário apresentado, o artigo tem por objetivo relatar a investigaçãoação realizada com mães de filhos com DI, no sentido contribuir para a compreensão acerca da participação em grupos de encontros e seus impactos na qualidade de vida e ressignificação de seus projetos de vida, uma questão pertinente visto que as pesquisas indicam esses ganhos como possibilidades. Contudo, não foi identificada nenhuma pesquisa empírica que avaliasse efetivamente tais resultados.

\section{Método}

Participaram da investigação-ação dois grupos de mães de alunos da Associação de Pais e Amigos dos Excepcionais (APAE) de uma cidade do interior de Minas Gerais. $O$ grupo 1, constituído por seis mães, e o grupo 2, constituído por cinco. A idade das participantes variou entre 27 e 60 anos, e a de seus filhos entre 3 e 39 anos. Todas elas são donas de casa, caracterizando-se como "do lar", pelo motivo de dedicarem-se aos cuidados do filho, e a renda familiar varia entre 1 e 3 salários mínimos. Todas as mães tinham até o Ensino Fundamental completo. Como critério de inclusão para participação nos grupos, foi considerado o fato de ser mãe ou cuidadora principal de uma pessoa com deficiência intelectual. Após a aprovação pelo Comitê de Ética, foi feita a apresentação da proposta de ação à APAE e obteve-se assentimento para a realização da mesma na Associação. Assim, as mães dos alunos foram convidadas a participar sendo garantido o caráter voluntário da participação, mediante consentimento livre e esclarecido. Foi utilizado questionário contendo dados sociodemográficos, visando caracterizar as participantes, no 
http://dx.doi.org/10.5902/198468640373

início da pesquisa, e aplicada a Escala de Mudança Percebida (BANDEIRA et al., 2009) após a ação.

Com o grupo 1, as intervenções foram realizadas semanalmente durante o primeiro e o segundo semestre de 2017, perfazendo um total de 24 encontros com duração de uma hora, sendo 12 encontros em cada semestre; e, com o grupo 2, as intervenções foram realizadas durante o segundo semestre de 2017, em um total de 12 encontros com duração de uma hora e meia, mantendo-se estrutura similar de condução nos dois grupos realizados. No término das intervenções, foi aplicada a Escala de Mudança Percebida (BANDEIRA et al., 2009). A Escala utilizada visa analisar as mudanças percebidas, a partir de uma autoavaliação de cada participante, como resultado da ação, e inclui 19 itens, separados em três grupos: Atividades e Saúde Física, Aspectos Psicológicos e Sono e Relacionamentos e Estabilidade Emocional.

Todas as respostas das participantes ao questionário e à Escala de Mudança Percebida foram registradas no banco de dados do programa de informática - SPSS for Windows 20.0 (Statistical Package for Social Sciences) - com o objetivo de facilitar a aplicação das técnicas estatísticas. A apresentação e análise dos dados envolveram a utilização de técnicas de estatística descritiva.

A investigação-ação caracterizou-se por atividades grupais, desenvolvidas de forma coletiva e estruturada a partir de dinâmicas de grupo, ou seja, tarefas lúdicas, possibilitando a construção de vínculos entre os membros, com o objetivo de ressignificar condutas a partir do referencial operativo, tanto individual quanto grupal (AFONSO, 2010; PICHÓNRIVIÈRE, 1988). Nessas intervenções foram trabalhadas questões relacionadas ao vínculo do grupo; preconceito; limites e possibilidades dos filhos; avaliação dos projetos de vida; direitos e deveres da pessoa com DI. O Inventário de Habilidades de Vida Independente (LIMA; BANDEIRA; GONÇALVES, 2003) foi utilizado como um disparador para as discussões.

Este Inventário foi criado com a finalidade de obter o ponto de vista de parentes ou cuidadores de pacientes psiquiátricos com doença mental grave sobre o ajustamento social deste, avaliando a maior ou menor capacidade que o paciente tem de cuidar de si mesmo e de seus interesses. Dessa forma, foi utilizado com o intuito de promover uma reflexão acerca daquilo que os filhos fazem sozinhos, aquilo que podem vir a fazer e meios para conquistar tal independência. Não foi identificado nenhum instrumento similar validado no país para pessoas com deficiência intelectual, tendo sido feita uma utilização qualitativa do 
http://dx.doi.org/10.5902/198468640373

instrumento, ou seja, discussões dentro do grupo acerca de cada item proposto pelo Inventário. Foram realizadas observações sistemáticas de cada encontro (todas as falas eram registradas) e confecções de relatórios sobre estes com o objetivo de analisar o funcionamento do processo grupal a partir do referencial teórico de Pichón-Rivière (1988) e Afonso (2010).

Para avaliação das intervenções, foram realizadas análises do processo grupal (com foco nas principais dificuldades dos grupos), a partir do referencial proposto e Análises de Conteúdo (BARDIN, 1994) das observações registradas, no qual foram elencadas as principais categorias emergentes no discurso das participantes. A Análise de Conteúdo consiste em três etapas, sendo a primeira a pré-análise, que se trata da fundamentação e organização das possíveis interpretações dos resultados encontrados. Na segunda etapa, denominada exploração do material, é realizada a codificação dos dados por meio dos registros, e, por último, na categorização, são elencadas as principais categorias emergentes no discurso (CAREGNATO; MUTTI, 2006).

\section{Resultados e discussão}

Um dos principais objetivos da investigação-ação foi avaliar os impactos da participação em grupos de mães de pessoas com DI, na qualidade de vida delas e na ressignificação de seus projetos de vida. Para isso, inicialmente foi proposto um resgate da história das mães a partir do momento de virada em suas vidas, aquele do nascimento do filho com DI, em que cada uma teve a oportunidade de contar sobre suas vivências e falar sobre seus sentimentos em meio a tal experiência. Após isso, para alcançar a meta pretendida, foram escolhidas dinâmicas de autoestima e autoconhecimento, no intuito de promover às participantes a possibilidade de reflexão sobre seus papéis, não só de mães, como também de mulheres, e depois chegou-se ao tema de projetos de vida.

A partir do momento em que este tema foi introduzido no grupo, observou-se que as mães apresentavam dificuldade para pensar em um projeto de vida próprio, sem envolver a vida dos filhos - que se mostravam extremamente dependentes de seus cuidados intensos, evidenciando, assim, a sobrecarga vivenciada por elas. Em consonância com esta afirmação, pesquisa realizada por Bastos e Deslandes (2008), sobre a narrativa de mães em relação à experiência de ter um filho com DI, identifica que os protagonistas das narrativas das mães são sempre os filhos, já que suas vidas passam a girar em torno deles, que necessitam de constantes cuidados. 
http://dx.doi.org/10.5902/198468640373

Além disso, uma das revelações mais sólidas em pesquisas com famílias de pessoas com DI é a questão da sobrecarga materna (WALDMAN; SWERDLOFF; PERLMAN, 1999; PEREIRA-SILVA; DESSEN, 2004). Também é frequente encontrar na literatura que esta tem um impacto negativo sobre a saúde e bem-estar das mães, sucedendo em níveis de estresse altamente prejudiciais (PEREIRA-SILVA; DESSEN, 2004; BASTOS; DESLANDES, 2008). Pesquisas realizadas por Bastos e Deslandes (2008) e Waldman, Swerdloff e Perlman (1999) afirmam que os pais são menos envolvidos em relação aos cuidados dos filhos, principalmente quando eles têm deficiência e, portanto, muitas vezes a participação do marido, quando acontece, é em relação ao sustento da casa evidenciando a dimensão do problema. De acordo com as narrativas desta investigaçãoação, sete, das onze participantes, não obtiveram apoio de familiares e nem do pai da criança, principalmente no início do diagnóstico: "Ele tava dando muita convulsão, ele teve que sair da escola e vir pra APAE. Aí meu marido não aceitou, disse que eu não vinha", "Gente, eu tava em Belo Horizonte meu marido me ligando falando que roupa veste no R., o que ele vai comer. Ah, pelo amor de Deus gente!”, "O pai dele não queria aceitar de jeito nenhum. Se eu tivesse ouvido ele, não tinha desenvolvido nada".

Dessa forma, foi possível compreender o movimento realizado pelo grupo: o que a princípio foi interpretado como um bloqueio em relação ao tema de projeto de vida, posteriormente, a partir de seu amadurecimento, passou a ser entendido como um elemento comum que compôs um projeto de vida coletivo - isto é, devido ao problema de sobrecarga vivenciado por todas (identificado ao longo do processo), o projeto de vida do grupo envolvia a busca por formas de enfrentamento deste problema, o que, consequentemente, envolvia lidar com a dependência/ desenvolvimento da independência dos filhos.

Por isso, na continuação do processo grupal, o foco foi o desenvolvimento do tema "limites e possibilidades dos filhos". Identificou-se pesquisa que indicava a importância de trabalhar com as mães a questão da superproteção e da independência dos filhos antes de discutir sobre o projeto de vida das mães e da própria pessoa com DI (CARVALHO; ARDORE; CASTRO, 2015). No entanto, não havia orientação de como fazer para que essa reflexão fosse efetiva o suficiente para produzir possibilidades de mudança. Além disso, entende-se, a partir desta investigação-ação, que tais questões, por si só e pelo propósito que compreendem, compõem um desenho de projeto de vida. Assim sendo, para realizar essa reflexão de uma maneira mais concreta, facilitando a compreensão das mães e a 
http://dx.doi.org/10.5902/198468640373

identificação de atividades simples e cotidianas que os filhos poderiam realizar, foi feita uma busca na literatura científica e identificado o Inventário de Habilidades de Vida Independente (LIMA; BANDEIRA; GONÇALVES, 2003), desenvolvido com o objetivo de avaliar habilidades de vida independente de pacientes psiquiátricos com doença mental grave e persistente com impacto em diversas áreas da vida cotidiana. As questões versavam sobre os seguintes aspectos da vida cotidiana: alimentação; cuidados pessoais; atividades domésticas; preparo e armazenamento de alimentos; saúde; administração do dinheiro; transporte; lazer e emprego. Optou-se, então, por utilizar esse inventário como disparador para aspectos relacionados a limites e possibilidades dos filhos, a fim de que as mães pudessem conversar sobre a capacidade dos filhos, refletindo sobre como promover o mínimo de autonomia possível a eles, em passos gradativos.

O trabalho com o Inventário de Habilidades de Vida Independente nos grupos possibilitou que as mães discorressem minuciosamente sobre as atividades diárias realizadas ou não pelos filhos, de acordo com a capacidade de cada um. Dessa forma, constatou-se que, de 84 itens do questionário sobre as habilidades desenvolvidas pelos filhos, poucos deles realizavam algumas tarefas pontuais, ainda que tivessem capacidade para mais. De acordo com os relatos, as próprias mães afirmavam que se sentiam sobrecarregadas devido ao fato de elas mesmas não promoverem alguma autonomia em seus filhos: "Essa coisa deles não fazer as coisas é culpa nossa de não incentivar eles desde pequenino... No caso do J., eu que não ensinei ele...", "O meu filho eu sei porque ele tá assim, acostumei ele mal, é mais fácil fazer para ele do que ensinar e esperar ele fazer".

De acordo com Glat (1992), preocupações e dificuldades cotidianas associadas à incerteza sobre o nível de autonomia do filho resultam numa postura de superproteção, limitando suas possibilidades de desenvolvimento. E, quanto mais prolongada esta dependência, maior a falsa sensação de imaturidade e irresponsabilidade em relação à pessoa com deficiência intelectual (LITTIG et al., 2012). Dessa forma, inevitavelmente, as mães questionam se, no futuro, seus filhos vão adquirir maturidade, podendo ser independentes, estendendo seus cuidados até a vida adulta (COLL; MARCHESI; PALACIOS, 2004).

Como consequência do que foi citado, a falta de limites também se mostrou como um emergente no comportamento dos filhos, exemplificada pelos relatos: "Aquele dia eu fui embora ele falava comigo na maior altura, gritava comigo - essa gorda, com essa cara 
http://dx.doi.org/10.5902/198468640373

redonda. Eu olhava com a cara feia pra ele, ele ficava pior. Quando eu desci do ônibus do nada ele me deu um empurrão, fui parar do outro lado", "Ele é agitado, briga comigo, me xinga...", "o J. estava fazendo hora, não quis tomar banho para vir aqui para a APAE, ele acha que vai me controlar, mas cansei...", "o meu é meio ao contrário, colocar roupa não põe, mas tirar sim, comer direito não, mas soprar tudo sim... como ele sabe se me chamar não acordo já começa socando o pé na minha cara, e te bate...".

A partir da investigação-ação, ainda que algumas mães fossem de filhos pequenos que não tinham alcançado idade para realizar certas atividades, foram propiciados momentos de reflexão acerca do que é ou não possível ser realizado pelos filhos, sobre a questão da importância do limite, além de troca de experiências sobre como atingir algum objetivo, ou seja, quais estratégias poderiam ser utilizadas para se alcançar tal comportamento no filho. Dessa forma, as participantes puderam compreender como algumas coisas podem ser feitas e um novo horizonte de possibilidades foi aberto: "Gostei para ver aonde a gente tá errando e fazendo certo", "Eu gostei porque vi que tem muita coisa que o F. dá conta de fazer. Também gostei porque é muito detalhado, fala de tudo que está relacionado ao dia-a-dia deles", "Também gostei porque deu para a gente ver melhor que tem muita coisa que eles podem fazer sem a nossa ajuda". De acordo com Nobre, Montilha e Temporini (2008), as atividades desenvolvidas no processo grupal auxiliam as mães em uma melhor compreensão dos filhos, o que envolve tanto o seu desenvolvimento e as implicações da deficiência, podendo, então, valorizar as suas potencialidades. Além disso, resultados de um programa de orientação de pais em grupo trazem a hipótese de que, a partir da intervenção, os pais são capazes de ampliar o conjunto de estratégias educativas direcionadas aos filhos (NEUFELD et al., 2018).

Considera-se que, tanto a partir das discussões em grupo quanto a partir do uso do instrumento Inventário de Habilidades de Vida Independente, foi possível oferecer parâmetros de critérios de independência dos filhos às mães, trocar experiências de como colocar limites, investindo na autonomia e desenvolvendo capacidades em ambos. Para mais, somente após um trabalho relacionado à independência dos filhos, de modo a aliviar a sobrecarga das mães, é que se torna possível a elas pensar em outros novos projetos de vida, tendo a oportunidade de fazer planos para si e vislumbrar mudanças, o que ainda se mostrava paralisado no grupo.

Neves e Cabral (2008) demonstram que mães e cuidadoras buscam maneiras para o desenvolvimento do cuidado de forma solitária, constituindo tal busca numa fonte de 
http://dx.doi.org/10.5902/198468640373

sofrimento e estresse. Assim, afirmam que o compartilhamento de experiências e vivências não só enriquece conhecimentos e informações, mas também se constitui como uma importante fonte de empoderamento coletivo. O processo de empoderamento implica a reflexão acerca da realidade, de uma consciência crítica, e da liberdade para a tomada de decisões com informações suficientes para tal (KAR; PASCUAL; CHICKERING, 1999). De acordo com Neves e Cabral (2008), quando empoderada, a mãe da pessoa com DI pode requerer direitos, exercer a cidadania e tomar decisões compartilhadas com os profissionais, de forma a garantir melhor qualidade de vida para o filho - e para si.

O grupo mostrou-se, durante a investigação-ação, como um lugar propício ao acolhimento e troca de experiências mais do que encontravam em seus contextos cotidianos. Outro aspecto importante é o de estar em grupo dedicando um determinado tempo para pensar e discutir sobre suas vivências, criando condições para uma revisão sobre a forma que educam seus filhos para que superem suas dificuldades, como fazem e o que poderia ser mudado. Tais afirmações podem ser exemplificadas pelas falas: "Só de vir aqui ter elas apoiando em nossos problemas, ver o que cada uma está passando, uma apoia e dá força a outra", "E gente, cuide de vocês primeiro pra depois cuidar dos seus, e se vocês não tiver bem, eles não vão estar... Conversando a gente vê que o problema da gente é tão grande como a gente tá propondo pra gente mesmo" e "A gente quando entrou, cada uma tem uma história né. A gente ficava no Clube naquele alvoroço, mas não conversava assim".

Com base nos demais temas trabalhados durante o processo grupal e das análises de conteúdo realizadas, três categorias foram elencadas de acordo com os principais assuntos emergentes durante os encontros. São elas: Resgate da história de mãe de pessoa com DI, Saúde mental e Preconceito.

\section{Resgate da história de mãe de pessoa com DI}

Um dos primeiros temas trabalhados nos grupos foi identidade de mãe de PCDI, o qual foi proporcionado um espaço de escuta para que cada participante pudesse compartilhar sua história em relação ao primeiro contato com a DI, os sentimentos iniciais e as formas de adaptação à situação, a fim de que pudéssemos conhecer e compreender a história de cada uma delas.

A partir dos relatos constatou-se que os sentimentos de frustração, culpa e incertezas foram frequentes no primeiro momento para as mães, bem como ressaltados por Klaus, 
http://dx.doi.org/10.5902/198468640373

Kennell e Klaus (2000), Bastos e Deslandes (2008) e Falkenbach, Drexsler e Werler (2008). Tais sentimentos foram seguidos de adaptação e enfrentamento da situação, o que Klaus, Kennell e Klaus (2000) caracterizam como fases de reação sócio-psíquica - luto, adaptação e aprendizado. Estudo realizado com mães de pessoas com paralisia cerebral por Smeha et al. (2017) também confirma tal resultado, ressaltando um choque inicial no primeiro contato, causando insegurança e medo. Dessa forma, esta categoria ressalta as dificuldades e elaborações da nova identidade formada pelas mães após o nascimento da criança, exemplificada pelas falas: "Por que com meu filho, por que com meu filho? Tinha vez que eu chorava, eu falava, gente o que eu vou fazer?", "No começo eu não aceitava não, chorava muito, mas depois vi que aqui era bom".

Segundo Mannoni (1999), dificilmente o filho com deficiência vai fazer parte das expectativas da mãe, o que dificulta uma consolidação positiva de sua identidade tanto de mãe quanto de mulher. Solomon (2012) aponta que, geralmente, as pessoas não estão preparadas para lidar com filhos que apresentam necessidades desconhecidas, sendo que a maternidade é uma experiência de relação permanente com um estranho. Por isso, quanto mais alheios, mais forte é a sensação de negatividade causada, o que justifica os sentimentos experimentados pelas mães nesse momento.

Sobre essa questão, Falkenbach, Drexsler e Werler (2008) consideram compreensíveis tais sentimentos e reações perante uma situação inédita e compreendem que pais e mães são capazes de reavaliar seus conceitos e aprender a valorizar as potencialidades dos filhos com deficiência. Garro e Mattingly (2000) afirmam o início da construção de duas identidades: a da criança, que agora possui a DI, e a da mãe, que se dedicará integralmente ao cuidado com o filho, redefinindo os projetos futuros à nova realidade. $O$ que corrobora com os resultados encontrados nesta ação, podendo ser observado a partir de relatos como: "Tudo que tiver ao meu alcance eu faço por ele... (...) Tudo que faço é para o ideal dele", "Primeiro você fala "por que comigo?", depois você fala "que bom que é comigo" (...) Não dá pra ficar pensando por que? Quem é o culpado? Foi médico? É de família? Você tem que seguir em frente. Abraçar a causa".

\section{Saúde mental}

As participantes dos grupos, a partir de seus relatos, consideravam-se incapazes de relaxar ou ter algum momento de lazer, trazendo o cansaço como consequência. Sintomas de autoestima baixa e depressão foram citados em alguns momentos dos encontros, como 
http://dx.doi.org/10.5902/198468640373

nas falas: "Eu não sou capaz de relaxar, meu relaxamento é trabalhando, ou é na cozinha ou na máquina, não consigo sentar na TV, na hora eu durmo e acordo até estressada", "Eu tenho uma vida muito sofrida. Eu não gosto de ficar na minha casa. Eu não tenho vontade fazer nada ali, tenho vontade sumir.", "Eu espero melhorar o quadro de depressão, autoestima... Porque pra mim é muita coisa, porque eu levo ele em todos os lugares, mas eu mesma não faço nada pra mim né", "Tudo pra mim tá ruim, às vezes eu me sinto mal no meio das minhas amigas, às vezes eu tô distante, mas eu não sou assim".

Na sociedade contemporânea, o papel da mulher na família é de prover assistência diária principalmente para os membros mais vulneráveis, mantendo um papel específico e estratégico no cuidado, além de cumprir as tarefas de casa (CAVALCANTE et al., 2016; SCHMIDT; DELL'AGILO; BOSA, 2007). Dessa forma, esta mulher se mantém como cuidadora principal desses membros, no caso, filhos com DI, até o envelhecimento de ambos (CARVALHO; ARDORE; CASTRO, 2015; SCHMIDT; DELL'AGILO; BOSA, 2007), sendo esta, uma responsabilidade e uma obrigação moral socioculturalmente construída, que se constitui como uma fonte de estresse crônico - podendo afetar sua saúde física e mental e seu bem-estar (NEVES; CABRAL, 2008).

Em muitas culturas, o desenvolvimento de doenças físicas é associado a problemas familiares ou na comunidade, constituindo, segundo Kirmayer e Groleau (2001), um fenômeno denominado sociossomatização. Assim, é possível afirmar que, dependendo da estrutura social que a mulher está inserida - o que envolve a rede social, familiar e cultural - diferentes respostas ao estresse estabelecido podem aparecer. Como uma reação psicossocial ao estresse, o sofrimento pode manifestar-se através de emoções negativas como a ansiedade e a depressão (BRESLAU, 2003; RAINA et al., 2004).

Neves e Cabral (2008), em seus estudos, concluíram que a dedicação exclusiva ao atendimento das demandas de cuidados de sobrevivência da criança refletiu-se no bemestar das cuidadoras, ocasionando um desgaste físico, emocional e afetivo. Na presente investigação-ação, foi identificada a falta de tempo para ser mulher, o sentimento de estar perdendo vários direitos de vida e de convivência, como ir ao médico, dormir, sentir prazer e até mesmo, como destacado em pesquisa realizada por Cavalcante et al. (2016), o "direito de morrer" são aspectos que chamam atenção.

A partir disso, o grupo atribuiu importância à presente atividade realizada, como um investimento em melhorar essas condições em relação a si mesmas, já que as mesmas reconhecem que para conseguir cuidar bem dos filhos, precisam estar bem consigo. 
http://dx.doi.org/10.5902/198468640373

Exemplos disso são algumas falas: "Nós mães sempre precisamos de psicóloga, a APAE sempre tinha que fornecer isso pra nós, a gente não tem condição de pagar, a gente tem que tá bem pros filhos tá bem, porque a gente não tá bem, eles sentem", "No décimo encontro eu notei a melhora, eu era muito impulsiva, brigona, nervosa, agitada. Lá em casa ninguém tava me aguentando. O G. já estava mordendo os dedos, eu era nervosa e estava passando isso pro menino".

\section{Preconceito}

O preconceito em relação aos filhos com DI foi abordado por muitas mães, demonstrando-se relevante, principalmente, no que diz respeito ao uso da palavra "doente" para referir-se às PCDI, sendo esta uma palavra de conotação pejorativa dentro desse contexto. Tal tratamento inadequado parte de pessoas desconhecidas, conhecidas e até mesmo de familiares. Omote (1995) destaca a coletividade enquanto esfera identificadora da deficiência, já que a deficiência não existe por si só, mas perante determinadas circunstâncias; assim como Vygostski (1931/1997) que aponta que as características da criança com deficiência não são definidas pelo núcleo biológico, mas sim pelo social. Em pesquisas realizadas por Falkenbach, Drexsler e Werler (2008) e Paixão (1997), mães de PCDI entrevistadas relatam sentir como se fosse para si toda a depreciação direcionada ao filho, e, por isso, segundo Mannoni (1999), a luta travada contra as dificuldades em relação aos filhos não deixa de ser uma luta por si mesmas.

A partir das seguintes falas trazidas pelo grupo, é possível observar tanto a visão conturbada da sociedade perante a deficiência, como a forma como as mães reagem perante o preconceito, prontas para defenderem os seus filhos: "uma senhora falou - que menino bravo, será quem é a mãe dele? Vou rezar para você conseguir cuidar dele", "Uma vez eu briguei feio lá com minha família que fica falando que meu filho é doente" e "Nossa, quando meu menino entrou aqui, chamou meu filho de doente, nossa foi uma briga feia".

Foi também citado um preconceito institucional com alunos da APAE, que muitas vezes são associados com um estereótipo pejorativo para os deficientes intelectuais. Além disso, o desconhecimento sobre o comportamento das pessoas com deficiência intelectual também leva as pessoas a sentirem medo e evitarem contato. Tal afirmação pode ser demonstrada a partir das falas: “... aí fala, tadinho, deixa ele, ele estuda na APAE”, "Também tinha uma vizinha que tinha medo de crianças da APAE, depois que ela conheceu 
o J. ela mudou esse pensamento" e "O R. pôs a mão, a menina: ai meu Deus eu pensei que ele ia me agredir".

Para Batista e França (2007, p. 121), "a sociedade bem-sucedida é aquela que favorece, em todas as áreas, a convivência humana e o respeito à diversidade que a constitui". A partir dos relatos, é possível identificar o despreparo da sociedade em lidar com as diferenças, vivenciado por essas famílias. Entretanto, as pessoas constituem-se a partir de sua interação com outros indivíduos, ou seja, através de grupos, participando de coletivos e estando dentro do coletivo que, em geral, constitui a sociedade a qual compõe (FLEURY-TEIXEIRA et al., 2008). Portanto, mostra-se de extrema importância o desenvolvimento de mecanismos que possam promover a autonomia do indivíduo que ampliem suas capacidades de intervenção com o outro, começando por sua interação na família.

\section{Avaliação pós ação}

De acordo com as análises quantitativas, foi possível verificar que, em relação às Mudanças Percebidas (BANDEIRA et al, 2009), foram identificadas percepções de modificações para melhor no fator Aspectos Psicológicos e Sono (90,9\% das mães se sentiam melhor do que antes e 9,1\% sem mudanças). Esse fator refere-se à confiança em si próprio, interesse pela vida, humor, capacidade de lidar com situações difíceis da vida e sono. No fator Relacionamento e Estabilidade Emocional, foram verificadas as mesmas proporções de modificações ((90,9\% das mães sentiam-se melhor do que antes e 9,1\% sem mudanças). Esse fator refere-se à convivência com as pessoas e à estabilidade das emoções. No fator relacionado às Atividades e Saúde Física, foram verificadas as menores mudanças (63,6\% sentiam-se melhor do que antes e 36,4\% sem mudanças). Esse fator refere-se às mudanças percebidas em relação às atividades de lazer, energia, realização das tarefas de casa, capacidade de cumprir obrigações e tomar decisões, interesse em trabalhar ou ocupar-se com alguma coisa, assim como sua sexualidade, apetite e saúde física. Essas mudanças percebidas revelam transformações importantes na forma como as mães sentiram-se após a pesquisa-ação realizada, indicando sua potencialidade para intervenções com esse público.

\section{Conclusões}


http://dx.doi.org/10.5902/198468640373

A realização desta investigação-ação permitiu verificar empiricamente alguns impactos da participação em grupos de encontros de mães de pessoas com DI e a importância da condução desses trabalhos por profissionais com formação em psicologia. Observou-se que, a partir do objetivo inicial de trabalhar a qualidade de vida das mães e a ressignificação de seus projetos de vida, foi possível identificar um projeto de vida coletivo, a ser desenvolvido a partir de um problema em comum vivenciado por todas as integrantes do grupo - a sobrecarga advinda de cuidados intensos e constantes aos seus filhos. Tal problema decorre devido às dificuldades concretamente sentidas pela maior parte desta população e que são pouco trabalhadas no sentido de acreditar e investir na capacidade dos filhos para que eles tornem-se mais independentes e autônomos possíveis; de entender a importância do limite em relação aos comportamentos agressivos dos filhos, como possibilidade de ampliar as fronteiras das relações cotidianas e favorecer uma maior possibilidade de inclusão dos filhos nos diversos espaços sociais. A partir do trabalho desenvolvido, ficou evidente tanto nas falas das mães, quanto na análise das Mudanças Percebidas o aumento da energia das mães, de suas disposições para as atividades cotidianas, além da reflexão e do relato de que estavam trabalhando em casa para que os filhos pudessem ter uma vida mais independente, minimizando a sobrecarga delas no presente e no futuro.

Além disso, ficou evidenciada a importância de se trabalhar o vínculo da mãe com os filhos com DI, tendo por foco a necessidade de ressignificação das potencialidades dos filhos para a aprendizagem de cuidados consigo mesmos e com as demandas da vida diária como forma de geração de independência dos filhos e como possibilidade de melhorar a qualidade de vida das mães e de elas poderem resgatar projetos de vida abdicados quando do nascimento dos filhos. Essa reflexão sobre os vínculos precisa ser mediada pela busca concreta de estratégias para que os filhos aprendam a ser os mais independentes possíveis (comer sozinhos, tomar banho, escovar os dentes, trocar roupa, etc.). Trabalhar qualitativamente com o Inventário de Vida Independente (LIMA; BANDEIRA; GONÇALVES, 2003) permitiu discutir possibilidades concretas de ações a serem desenvolvidas com os filhos com DI.

Sugere-se como possibilidade de aplicação dos resultados da presente investigaçãoação que, em intervenções com as mães, trabalhe-se primeiro com estratégias para tornarem os filhos o mais independente possível, para depois trabalhar as questões da qualidade e projetos de vida específicos das mães. Isso porque é uma questão muito difícil 
http://dx.doi.org/10.5902/198468640373

para elas planejarem seu futuro sem perceber de fato que é possível haver mudanças nos seus filhos - o que faz com que evitem pensar no futuro e acomodem-se com uma vaga esperança de melhorias, sem considerar o processo que tornaria isso real. Pesquisas são necessárias para ampliar as estratégias de ação com mães de pessoas com DI que possam efetivamente contribuir com elas, com seus filhos e com a construção de possibilidade de formação de psicólogos em melhores condições de contribuir para a maior qualidade de vida das pessoas com quem atuam.

\section{Referências}

AFONSO, Maria Lúcia Miranda. Oficinas em dinâmica de grupo: um método de intervenção psicossocial. 3. ed. São Paulo: Casa do Psicólogo, 2010. p 171.

AMERICAN ASSOCIATION ON INTELLECTUAL AND DEVELOPMENTAL DISABILITIES / AAIDD. 2010. Disponível em http://www.aamr.org/content_104.cfm. Acesso em: 23 ago. 2019.

BANDEIRA, Marina. et al. Avaliação de serviços de saúde mental: adaptação transcultural de uma medida da percepção dos usuários sobre os resultados do tratamento. Jornal Brasileiro de Psiquiatria, Rio de Janeiro, v. 58, n. 2, p. 107-14, 2009

BASTOS, Olga Maria; DESLANDES, Suely Ferreira. A experiência de ter um filho com deficiência mental: narrativas de mães. Cadernos de Saúde Pública, Rio de Janeiro, v. 24, n. 9, p. 2141-2150, set. 2008.

BATISTA, Sérgio Murilo; FRANÇA, Rodrigo Marcelino. Família de pessoas com deficiência: desafios e superação. Revista de divulgação técnico-científica do ICPG, Florianópolis, v. 3, n. 10, 117-121, jan./jun. 2007.

BARDIN, Laurence. Análise de Conteúdo. Lisboa: Edições 70, 1994. 225 p.

BEMISTER, Taryn. et al. Predictors of caregiver depression and family functioning after perinatal stroke. BMC pediatrics, United Kingdom, v. 15, n. 1, p. 1-11. 2015.

BRESLAU, Erica. The continuum: somatic distress to medicalization in women with breast cancer: theoretical and empirical assessment. In: SEGAL, Marcia Texler; DEMOS, Vasilikie. (Orgs.). Gender perspectives on health and medicine: key themes. Toronto: Elsevier, 2003. p. 131-180.

CAREGNATO, Rita Catalina Aquino; MUTTI, Regina. Pesquisa qualitativa: análise de discurso versus análise de conteúdo. Texto \& Contexto - Enfermagem, Florianópolis, v. 15, n. 4, p. 679-684, out./dez. 2006.

CARVALHO, Cláudia Lopes; ARDORE, Marilena; CASTRO, Leila Regina. Cuidadores Familiares e o Envelhecimento da Pessoa com DI: Implicações na prestação de cuidados. 
http://dx.doi.org/10.5902/198468640373

Revista Kairós Gerontologia, São Paulo, v. 18, n. 3, p. 333-352, jul./set. 2015.

CARVALHO, Elenice Natália Soares; MACIEL, Diva Maria Moares de Albuquerque. Nova concepção de deficiência mental segundo a American Association on Mental Retardation AAMR: sistema 2002. Temas em Psicologia da SBP, Ribeirão Preto, v. 11, n. 2, p. 147-156, 2003.

CAVALCANTE, Fátima. Família, subjetividade e linguagem: gramáticas da criança "anormal". Ciência e Saúde Coletiva, Rio de Janeiro, v. 6, n. 1, p. 125-37, jan. 2001.

CAVALCANTE, Fátima Gonçalves. et al. Impactos de um documentário sobre o cotidiano de mães e filhos com deficiência: uma análise de cinedebates. Ciência e saúde coletiva, Rio de Janeiro, v. 21, n. 10, p. 3071-3080, out. 2016.

CHACON, M. C. Deficiência mental e integração social: o papel mediador da mãe. Revista Brasileira de Educação Especial, Piracicaba, v. 3, n. 5, p. 87-96, set. 1999.

COLL, César; MARCHESI, Álvaro; PALACIOS, Jesús. Desenvolvimento psicológico e educação: Transtornos de desenvolvimento e necessidades educativas especiais. 2. ed. Porto Alegre: Artmed, 2004. 368 p.

COPPUS, Antonia. People with intellectual disability: What do we know about adulthood and life expectancy? Research in Developmental Disabilities, United States of America, v. 18, n.1, p. 6-16, 2013.

CORCORAN, Jacqueline; BERRY, Amber; HILL, Stephanie. The lived experience of US parents of children with autism spectrum disorders: a systematic review and metasynthesis. Journal of Intellectual Disabilities, United Kingdom, v. 19, n. 4, p. 356-366, mar. 2015.

DOUMA, Jolanda; DEKKER, Marielle; KOOT, Hans. Supporting parents of youths with intellectual disabilities and psychopathology. Journal of Intellectual Disability Research, United Kingdom, v. 50, p. 570-581,ago. 2006.

FALKENBACH, Atos Prins; DREXSLER, Greice; WERLER, Veronica. A relação mãe/criança com deficiência: sentimentos e experiências. Ciência e saúde coletiva, Rio de Janeiro, v. 13, n. 2, p. 2065-73, nov. 2008.

FLEURY-TEIXEIRA, Paulo. et al. Autonomia como categoria central no conceito de promoção de saúde. Ciência e Saúde Coletiva, Rio de Janeiro, v.13, 2115-22, nov. 2008.

GALLAGHER, Stephen. et al. Predictors of psychological morbidity in parents of children with intellectual disabilities. Journal of pediatric psychology, United Kingdom, v. 33, n. 10, p. 1129-1136, nov-dez. 2008.

GARRO, Linda; MATTINGLY, Cheryl. Narrative and the natural construction of illness and healing. Berkeley: University of California Press, 2000. 288 p. 
GLAT, R. A sexualidade da pessoa com deficiência mental. Revista Brasileira de Educação Especial, Piracicaba, v. 1, n. 1, p. 65-74, 1992.

HALEY, William; PERKINS, Elizabeth. A. Current status and future directions in family caregiving and aging people with intellectual disability. Journal of Policy and Practice in Intellectual Disabilities, United States of America, v. 1. n. 1, p. 24-30, mar. 2004.

INSTITUTO BRASILEIRO DE GEOGRAFIA E ESTATÍSTICA / IBGE. Censo

Demográfico 2010: Características gerais da população, religião e pessoas com deficiência. 2012. Disponível em:

http://www.ibge.gov.br/home/presidencia/noticias/imprensa/ppts/00000009352506122012 255229285110.pdf. Acesso em: 19 ago. 2019.

JERUSALINSKY, Alfredo. Psicanálise e desenvolvimento infantil. 4. ed. Porto Alegre: Artes e Ofícios, 2007. $318 \mathrm{p}$.

KAR, Snehendu; PASCUAL, Catherine; CHICKERING, Kirstin. Empowerment of women for health promotion: a meta-analysis. Social Science \& Medicine, United States of America, v. 49, n. 11, p. 1431-60, 1999.

KIRMAYER, Laurence; GROLEAU, Danielle. Affective disorders in cultural context. Psychiatric Clinics of North America, United States o America, v. 24, n.3, p. 465-78, set. 2001.

KLAUS, Marshall; KENNELL John; KLAUS Phillys. Vínculo: construindo as bases para um apego seguro e para a independência. Porto Alegre: Editora Artmed, 2000. 187 p.

LIMA, Lúcia Abelha; BANDEIRA, Marina; GONÇALVES, Sylvia. Validação Transcultural do Inventário de Habilidades de Vida Independente (ILSS-BR) para pacientes psiquiátricos. Jornal Brasileiro de Psiquiatria, Rio de Janeiro, v. 52, n. 2, p. 143-158, mar./abr. 2003.

LITTIG, Patrícia Mattos Caldeira Brant. et al. Sexualidade na deficiência intelectual: uma análise das percepções de mães de adolescentes especiais. Revista Brasileira de Educação Especial, Marília, v. 18, n. 3, p. 469-486, jul./set. 2012.

MANNONI, Maud. A Criança retardada e a mãe. São Paulo: Editora Martins Fontes, 1999. $193 \mathrm{p}$.

MARRON, Elena, et al. Burden on caregivers of children with cerebral palsy: predictors and related factors. Universitas Psychologica, Catalunya, v. 12, n. 3, p. 767-777, maio 2013.

MARTENS Laurie; ADDINGTON, Jean. The psychological well-being of family members of individuals with schizophrenia. Social Psychiatry and Psychiatric Epidemiology, Calgary, v. 36, n. 3, p. 128-133, mar. 2001.

MATSUKURA, Thelma Simões. et al. Estresse e suporte social em mães de crianças com necessidades especiais. Revista Brasileira de Educação Especial, Marília, v. 13, n. 3, 
p. 415-28, set./dez. 2007.

MISHLER, Elliot. Narrativa e identidade: a mão dupla do tempo. In: LOPES, Luis Paulo da Moita; BASTOS, Liliana Cabral. (Orgs.). Identidades recortes multi e interdisciplinares. Campinas: Editora Mercado das Letras, 2002. p. 97-122.

NEUFELD, Carmem Beatriz. et al. Programa de Orientação de Pais em Grupo: Um estudo exploratório na abordagem Cognitivo-Comportamental. Psicologia em Pesquisa, Juiz de Fora, v. 12, n. 3, p. 1-11, set./dez. 2018.

NEVES, Eliane Tatsch; CABRAL, Ivone Evangelista. Empoderamento da mulher cuidadora de crianças com necessidades especiais de saúde. Texto \& ContextoEnfermagem, Florianópolis, v. 17, n. 3, p. 552-560, jul./set. 2008.

NOBRE, Maria Inês Rubo de Souza; MONTILHA, Rúbia de Cássia letto; TEMPORINI, Edméa Rita. Mães de crianças com deficiência visual: percepções, conduta e contribuição do atendimento em grupo. Revista brasileira de crescimento e desenvolvimento humano, São Paulo, v. 18, n. 1, p. 46-52, 2008.

OMOTE, Sadao. A integração do deficiente: um pseudo-problema científico. Temas em Psicologia, Ribeirão Preto, v. 3, n. 2, p. 55-62, ago. 1995.

PAIXÃO, Adriana Gomes. Representações sociais e a síndrome de Down: entre o sofrimento e a sua superação. Arquivos brasileiros de pediatria, Rio de Janeiro, v. 4, n. 5, p. 141-6, 1997.

PEREIRA-SILVA, Nara Liana; DESSEN, Maria Auxiliadora. O que significa ter uma criança com deficiência mental na família? Educar em Revista, Curitiba, n. 23, p. 161183, 2004.

PICHÓN-RIVIÈRE, Enrique. O processo grupal. São Paulo: Martins Fontes, 1988. 296 p.

RABELO, Miriam Cristina; ALVES, Paulo César; SOUZA lara Maria. (Orgs.). Experiência de doença e narrativa. Rio de Janeiro: Editora Fiocruz, 1999. 264 p.

RAINA, Parminder. et al. Caregiving process and caregiver burden: Conceptual models to guide research and practice. BMC Pediatrics, United Kingdom, v. 4, n. 1, jan. 2004

RIBEIRO, Sandra Fogaça Rosa; YAMADA, Midori Otake; TAVANO, Liliam D' Aquino. Vivência de mães de crianças com deficiência auditiva em sala de espera. Psicologia em revista, Belo Horizonte, v. 13, n. 1, p. 91-106, jun. 2007.

SANTOS, Manoel Antonio; PEREIRA-MARTINS, Maria Laura de Paula Lopes. Estratégias de enfrentamento adotadas por pais de crianças com deficiência intelectual. Ciência e Saúde Coletiva, Rio de Janeiro, v. 21, p. 3233-3244, 2016.

SCHMIDT, Carlo; DELL'AGLIO, Débora Dalbosco; BOSA, Cleonice Alves. Estratégias de 
http://dx.doi.org/10.5902/198468640373

coping de mães de portadores de autismo: lidando com dificuldades e com a emoção.

Psicologia: Reflexão e Crítica, Porto Alegre, v. 20, n. 1, p. 124-131, 2007.

SMEHA, Luciane Najar. et al. Cuidando de um filho com diagnóstico de paralisia cerebral: sentimentos e expectativas. Psicologia em Estudo, Maringá, v. 22, n. 2, p. 231-242, jul. 2017.

SOLOMON, A. Longe da árvore: pais, filhos e a busca da identidade. São Paulo: Companhia das Letras, 2012. 1056 p.

TOMAZ, Rodrigo Victor Viana. et al. Políticas públicas de saúde para deficientes intelectuais no Brasil: uma revisão integrativa. Ciência e Saúde Coletiva, Rio de Janeiro, v. 21 , n. 1, p. 155-172, jan. 2016.

VYGOTSKI, Lev Semionovitch. La colectividad como factor de desarrollo del niño deficiente. In: VYGOTSKI, Lev Semionovitch. Obras Escogidas - Tomo V: Fundamentos de defectología. Madrid: Visor, 1931/1997.

WALDMAN, Barry; SWERDLOFF, Mark; PERLMAN, Steven. Children with mental retardation grow older. ASDC journal of dentistry for children, United States of America v. 66, n. 4, p. 266-72, jul.1999.

WARD, Cally; COOPER, Vivien. Prevention is better than cure.... Tizard Learning Disability Review, United Kingdom, v. 18, n. 4, p. 208-211, 2013.

YOONG, Amanda; KORITSAS, Stella. The impact of caring for adults with intellectual disability on the quality of life of parents. Journal of Intellectual Disability Research, United Kingdom, v. 56, n. 6, p. 609-619, jun. 2012.

\section{Correspondência}

Sarah Cecílio Fonseca - Universidade Federal de São João Del-Rei, Departamento de Psicologia, sala 2.07 (LAPIP/ NACE). Praça Dom Helvécio, n. 74, São João Del-Rei, Minas Gerais - Brasil.

CEP: $36301-160$

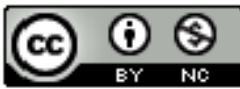

4.0 International (CC BY-NC 4.0) 